\title{
Causas de la emigración española actual: la "movilidad exterior" y la incidencia de la crisis económica
}

Causes of the current Spanish emigration: "external mobility" and the impact of the economic crisis

\author{
Juan Manuel Romero-Valiente \\ valiente@uhu.es \\ Centro de Investigación en Migraciones \\ Universidad de Huelva (España)
}

\section{Resumen}

Este artículo analiza las causas de la emigración española en el siglo actual, prestando especial atención a la más reciente. La metodología utilizada se basa fundamentalmente en la puesta en relación de datos procedentes de fuentes primarias y secundarias. Se concluye que los factores relacionados con la "movilidad exterior" han sido los principales catalizadores de este proceso hasta 2008-2010. A partir de dichos años, pero sobre todo desde 2011, los factores de expulsión asociados a la crisis económica y la agudización de sus efectos se erigen claramente en los principales responsables de su notable crecimiento.

Palabras clave: emigración española; causas; movilidad exterior; crisis económica.

\begin{abstract}
This paper analyzes the causes of Spanish emigration in the current century, paying special attention to the most recent one. The methodology used is fundamentally based on making connections between data from primary and secondary sources. It concludes that the factors related to "external
\end{abstract}


mobility" were the main catalysts of this process until 2008-2010. Since these years, especially since 2011, the factors of expulsion associated with the economic crisis and the worsening of its effects are clearly the main elements responsible for the remarkable increase in the rate of Spanish emigration.

Key words: Spanish emigration; causes; external mobility; economic crisis.

Agradecimientos: Este artículo es resultado de los trabajos de investigación que se llevan a cabo en el marco de los proyectos "Migraciones en y entre España y República Dominicana" (FUASDSEN, AACID) y "La emigración española actual: continuidades, cambios y tendencias" (Proyectos Puente-EPC, Universidad de Huelva). Deseo expresar mi agradecimiento al Dr. Antonio Luis Hidalgo Capitán (Universidad de Huelva) por su colaboración y apoyo en estas investigaciones.

\section{Introducción}

La emigración de españoles al exterior ha constituido desde el último tercio del siglo XIX hasta mediados de la década de los 70 del siglo XX uno de los fenómenos que más ha incidido en el desarrollo social y económico de España. Durante las últimas décadas del siglo XX y los primeros años del actual, la emigración española experimenta, probablemente con altibajos, una tendencia descendente, reduciéndose sensiblemente su magnitud respecto a períodos precedentes (Palazón, 1998). Este fenómeno, además, se ha visto opacado y prácticamente olvidado, ${ }^{1}$ tanto en el plano socio-político como académico, por el enorme impulso que ha experimentado la inmigración, tanto en forma de retorno de españoles como, sobre todo, de llegada de extranjeros (Romero-Valiente, 2003 y 2014; entre muchos otros).

Desde mediados de la primera década del siglo actual la emigración de españoles al exterior experimenta una inflexión que acaba derivando en cambio de tendencia y se traduce en un crecimiento continuado del número de salidas hasta la actualidad. Es, no obstante, desde finales de dicha década e inicios de la presente cuando el ritmo de crecimiento se acelera, elevándose sustancialmente el número de salidas que alcanzan en 2011 cifras (algo más de 55 mil) que no se registraban, al menos en las estadísticas oficiales, desde 1975 (Romero Valiente, 2012). En los últimos años el flujo ha seguido creciendo, situándose en el año 2015, según las estadísticas que publica el Instituto Nacional de Estadística (INE) de España (Estadística de Variaciones Residenciales, EVR; Estadística de Migraciones, EM), muy cerca de las cien mil salidas, el triple que en 2008, revirtiendo claramente el saldo migratorio.

1 Los pocos trabajos llevados a cabo en estos años se han centrado más en el stock de población española residente en el extranjero (Reques y de Cos, 2003; Romero-Valiente, 2003) y los procesos de retorno, que en el flujo emigratorio en sí, salvo en casos puntuales de determinados países (Romero-Valiente, 1998, 1999). 
Este notable, y en buena parte inesperado, crecimiento de la emigración española en los últimos años, ha suscitado una importante preocupación social y atención mediática, entrando incluso con cierta fuerza en la arena política. En este sentido, cabe reseñar que se mantiene desde el principio de la detección de este fenómeno un importante debate y controversia tanto sobre las magnitudes y características demográficas del mismo, como de las causas y motivaciones que lo alientan. La disparidad de las cifras, e incluso en las interpretaciones de las causas del fenómeno, ofrecidas en distintos trabajos (González Enríquez, 2013; González Ferrer, 2013; INJUVE, 2014; entre otros) viene, en todo caso, a poner en evidencia la necesidad de profundizar y mejorar en el análisis y conocimiento de estos flujos.

Las magnitudes de este fenómeno son, sin duda, muy superiores a las que indican las estadísticas oficiales que publica el INE debido al notable subregistro consular que afecta particularmente a los emigrados más jóvenes y quienes tienen como destino países de la Unión Europea (RomeroValiente, 2012; Romero-Valiente e Hidalgo-Capitán, 2014; Romero-Valiente, 2016; RomeroValiente, 2017a; Romero-Valiente, 2017b). Hecho, por otra parte, contrastado en las comparaciones efectuadas entre las estadísticas de emigración española (flujos de salida) a países europeos y las de inmigración (flujos de entrada) en los mismos (Poulain y Dal, 2008; Beer et al., 2010; González Ferrer, 2013; INJUVE, 2013; Romero-Valiente, 2016). En relación con ello, es muy probable que la composición y características sociodemográficas del flujo emigratorio también difieran en cierta medida de la que reflejan las estadísticas oficiales españolas (Romero-Valiente, 2016, 2017a). Especialmente en lo que respecta a los jóvenes, sobre todo entre 20 y 29 años, cuya participación en el flujo es, sin duda, muy superior tanto en términos absolutos como relativos.

En lo que respecta a las causas de la emigración tampoco existe unanimidad, evidenciándose apreciables diferencias entre la posición y el discurso oficial del Gobierno de España, y la realidad y percepción social de este fenómeno. Al menos, hasta hace bien poco. De una parte, el Gobierno de España, que tiene las principales competencias en materia de emigración, tanto el anterior del PSOE (2008-2011) como el actual del Partido Popular (2012-actualidad), han tratado de relativizar y restar importancia a este fenómeno (no así cuando han sido el partido en la oposición), así como su relación con la crisis económica y, sobre todo, con las políticas públicas por ellos implementadas. En el discurso oficial el crecimiento de la emigración se ha venido atribuyendo principalmente a factores relacionados con la denominada "movilidad exterior", 2 la cual se valora positivamente e

2 En una entrevista realizada a la Directora General de la Ciudadanía Española en el Exterior del Gobierno de España, Pilar Pin, publicada el 28 de abril de 2011 en distintos medios de comunicación españoles, ésta manifiesta que "no hay un flujo migratorio destacable que responda a motivos económicos", insistiendo en que la movilidad se ha convertido en un valor fundamental en la formación de los jóvenes profesionales (http://www.lavozdegalicia.es/lavozdelaemigracion/2011/04/28/00031303990605384599283.htm), negando asimismo que los jóvenes españoles estén abandonando el país por motivos económicos "en este 
incluso se alienta a través de medidas específicas (ayudas a la movilidad laboral en Europa a través de la acción "Tu trabajo EURES-FSE", etc.).

De otra, buena parte de los partidos políticos en la oposición y de los medios de comunicación, así como distintos especialistas en la materia, los cuales vinculan el crecimiento de la emigración principalmente con los efectos de la crisis económica y las políticas gubernamentales de austeridad y recortes del gasto público. En este caso, el discurso dominante asocia principalmente la emigración con la salida de jóvenes, nacidos y formados en España, con una elevada cualificación (la generación mejor preparada de nuestra historia), la cual estaría dando lugar a una auténtica sangría demográfica y fuga de cerebros. En este caso, la emigración se valora más como un problema que como una solución. Esta dicotomía y dualidad de discursos y posicionamientos ante la emigración no es nueva, habiendo estado presente ya un siglo atrás coincidiendo con la primera gran oleada emigratoria (Gil y Fernández, 2015).

En este contexto, el objetivo general de este trabajo es contribuir a mejorar el conocimiento de las causas de la emigración española en los primeros lustros del siglo actual, aportando datos, informaciones y análisis al debate abierto sobre este fenómeno. Sus objetivos específicos son identificar y analizar las principales causas de este fenómeno (motivaciones, factores generales condicionantes), así como tratar de calibrar el peso y protagonismo de las mismas a lo largo de su evolución durante dicho período.

Este trabajo se justifica por varias razones. Por un lado, por la escasez de investigaciones que aborden este tema tomando como punto de referencia una amplia base de datos e informaciones obtenidas directamente los propios protagonistas del fenómeno, y no solo de fuentes indirectas o secundarias (relación entre estadísticas de flujo migratorio y socioeconómicas). Por otra, por la inexistencia de investigaciones que aborden este fenómeno con cierta perspectiva temporal que no se ciña exclusivamente a los últimos años. Máxime teniendo en cuenta que la emigración comienza

momento la crisis no es un factor que desate la movilidad de los profesionales" (http://www.cronicasdelaemigracion.com/articulo/cronicas/pilar-pin-asegura-no-mas-emigrantes-hace-diezanos/20110428142643022545.html).

A principios de ese mismo mes de abril de 2011 la revista Actualidad Económica, relativamente afín al principal partido en ese momento de la oposición, incluía en su número mensual un reportaje titulado "Obligados a emigrar. La crisis y la incapacidad del Gobierno para generar esperanza empujan a miles de españoles al extranjero" (título de portada de dicho número). Por su parte, el 30 de noviembre de 2012 varios medios de comunicación se hacía eco de las manifestaciones, en un sentido parecido a la anterior, de la Secretaria General de Inmigración y Emigración del Gobierno de España, Marina del Corral, indicando que los jóvenes españoles no emigran por falta de oportunidades sino por espíritu aventurero, considerando además desvirtuados los discursos que sostienen que la salida de trabajadores cualificados de España esté estricta y únicamente vinculada a la situación de crisis (http://politica.elpais.com/politica/2012/11/30/actualidad/1354286966_753467.html). El 17 de abril de 2013 los medios de comunicación se hacían eco de las respuestas de la Ministra de Empleo y Seguridad Social, Fátima Bañez, a preguntas de la diputada socialista María González, en la que afirmaba que es verdad que hay muchos jóvenes que han salido España en busca de oportunidades por la crisis y que eso se llama movilidad exterior (http://www.lavozdegalicia.es/noticia/economia/2013/04/17/banez-califica-emigracion-jovenes-movilidadexterior/00031366188718167231120.htm). 
a crecer a mediados de la primera década del siglo actual en un contexto de elevado crecimiento económico y reducción del desempleo.

\section{Marco teórico y estado de la cuestión}

El estudio sobre las causas de las migraciones ha dado origen a un abundante cuerpo teórico (Massey et al., 1993; Martínez Veiga, 2000; Arango, 2003; García Abad, 2003; Jennissen, 2003; Alonso, 2006, 2011; Castles et al., 2014; entre muchos otros). Los trabajos llevados a cabo en últimas décadas ponen el acento en el carácter multi-causal de este fenómeno (Hidalgo-Capitán, 2013; entre otros) en el que intervienen e interactúan factores y motivaciones de diversa índole (económicos, sociales, psicológicos etc.) a diferentes niveles (desde el macroestructural hasta el microsocial).

Dada la complejidad del fenómeno migratorio, para su correcta comprensión se apuesta por el análisis a diversos niveles y la conjugación de perspectivas y metodologías procedentes de diversas disciplinas científicas. Los factores generales (de nivel macro o meso) se encuentran detrás de los motivos o razones específicas que aducen los protagonistas (individuos o familias) para explicar su decisión de emigrar. Los primeros contribuirían a explicar las tendencias más generales de la dinámica migratoria, mientras que los segundos pondrían en valor las dimensiones individuales y microsociales del proceso, posibilitando observar mejor los matices del mismo y el establecimiento de tipologías y perfiles de sus protagonistas. Ambos enfoques son útiles y complementarios para la comprensión correcta del fenómeno. ${ }^{3}$ Mientras que el primero prepara "el escenario", el segundo "representa la acción" (Ebanks, 1993). El presente artículo se lleva a cabo desde dicha perspectiva analítica.

En lo que respecta al estudio de la emigración española contemporánea (especialmente entre 1875 y 1975), buena parte de los trabajos llevados a cabo para explicar sus causas lo han hecho prestando especial atención a los factores generales (Vázquez y Estrada, 1992; Palazón, 1995; Sánchez Alonso, 1995; entre otros). Son relativamente menos numerosos, sin embargo, lo que prestan una especial atención a las motivos específicos de la decisión de emigrar (Rubio, 1973; Fernández de Pinedo, 1988; Vidal, 2005; entre otros). Ello está relacionado tanto con el enfoque analítico de los trabajos, como, sobre todo, con la posibilidad de disponer de datos sobre los

3 "No se pueden sobrevalorar los motivos individuales en detrimento de las causas estructurales cuando se trata de comprender el fenómeno de la migración, así como tampoco se puede prescindir del primero considerando sólo el segundo orden de factores" (Jannuzzi, 2000, p. 50).

"Migration analysis should be concerned not only with the reasons why people move or do not move, but also with the reasons why some places do or do not send or receive migrants. Thus, in migration studies it is equally important to associate the information derived from households and individuals with information on the communities in which they reside in order to know how the community-level and individual-level factors interact to affect the migration decision" (United Nations, 1982, p. 10). 
motivos para emigrar obtenidos a través de encuestas y/o informaciones sobre el particular recogidas en testimonios de los protagonistas.

Algo similar ocurre en lo que respecta a la emigración española más reciente, la cual ha generado un renovado interés por el tema y está dando lugar a numerosas aportaciones (Alba et al.,2013; Domingo y Sabater, 2013; Domingo et al., 2014; Domingo y Blanes; 2015; Domingo y OrtegaRivera, 2015; Alba y Fernández; 2015; Alarcón y Fernández, 2015; Barbulescu et al., 2015; DíazHernández et al., 2015; Arango, 2016; Kaczmarczyk \& Stanek, 2016; entre otros). En la gran mayoría de estos trabajos se hace referencia a los principales factores y motivos que explican este fenómeno. Son menos, sin embargo, los que llevan a cabo análisis, más o menos profundos, de los mismos tomando como base datos e informaciones primarias obtenidas a partir de los propios protagonistas (Romero-Valiente, 2012; INJUVE, 2013; OIM, 2014; González y Martínez, 2014; Faraco et alii, 2013; Moldes y Gómez, 2015; Rodríguez et al., 2015a, 2015b, 2016a, 2016b y 2017) o exclusivamente de carácter secundario procedentes de estadísticas migratorias y socioeconómicas (Izquierdo et al, 2014a, 2014b; De Marco y Sorando, 2015a, 2015b). ${ }^{4}$

Los resultados obtenidos en dichos trabajos, aunque coinciden generalmente en la identificación de los principales factores y motivos de la emigración, no son unánimes a la hora de valorar al peso específico de los mismos en la explicación de este fenómeno. En muy pocos casos, por otro lado, se lleva a cabo una ponderación del peso de los distintos factores y motivos en relación con la evolución temporal y crecimiento de la emigración.

\section{Fuentes y metodología}

Para la aproximación al fenómeno en estudio y tratar de alcanzar los objetivos indicados se ha utilizado una metodología mixta y de carácter triangular (Cantor, 2002; entre otros) basada principalmente en la puesta en relación de datos procedentes de fuentes primarias y secundarias. Los datos sobre las causas de salida de España (razones y motivos específicos de la emigración) han sido obtenidos directamente de los protagonistas a través una encuesta sobre la situación de los españoles en el extranjero realizada en 2012 (fuentes primarias). Los procedimientos seguidos para la realización de esta encuesta han sido explicados con detalle en trabajos precedentes (RomeroValiente, 2012; Romero-Valiente e Hidalgo-Capitán, 2014; Romero-Valiente, 2017a) y se resumen en la ficha técnica que aparece a continuación.

4 Hay que resaltar, por otra parte, que en los últimos años también se han publicado datos y análisis específicos sobre los factores y motivos para emigrar en el caso de ciudadanos de otros países que residen fuera de los mismos (Murray et al., 2012; MacAleer, 2013; Glynn et al., 2013; Triandafyllidou y Gropas, 2014; Biacabe ef Robert, 2014; Triandafyllidou \& Isaakyan, 2016; entre otros). Buena parte de ellos se han llevado a cabo respondiendo, sobre todo, a una preocupación generalizada por la denominada "fuga de cerebros" y a la alarma social et al., suscitada por la misma. Solo en el caso del estudio realizado por la Universidad de Cork (Glynn, 2013) se ofrecen datos sobre la evolución entre 2008 y 2013 del peso de los distintos motivos en la emigración. 
- Universo: españoles mayores de edad que llevan residiendo al menos un año (o tienen intención de hacerlo) en el extranjero

- Tamaño de la muestra: 4058 entrevistas válidas - residentes en 120 países- (2417 correspondientes a nacidos en España emigrados entre 2001 y 2012 con edades entre 18 y 64 años)

- Método de muestreo: no probabilístico por autoselección

- Recogida de información: encuesta on-line asistida por un sistema CAWI (Computer Assisted Web Interviewing)

- Fechas de realización (trabajo de campo): junio-septiembre 2012

En el cuestionario de la encuesta se incluyeron varias preguntas (cerradas y de respuesta obligatoria) destinadas específicamente a conocer las causas de la emigración. En este trabajo se han utilizado dos de ellas: la Bp1, en la que se recoge información sobre las principales causas de la salida de España (las variables consideradas son las que aparecen la Tabla 1); y la Bp3, en la que, a las personas que habían manifestado haber emigrado de España después de 2007, se les pedía que valoraran (mediante una escala del 1 al 7) la incidencia de la crisis económica en su decisión de emigrar. Los datos obtenidos han sido objeto de una exhaustiva explotación y tratamiento estadístico utilizando los programas Excel y SPSS. Los datos correspondientes a las respuestas a dichas preguntas han sido cruzados con los de otras variables de interés para los objetivos de este artículo, fundamentalmente el año de emigración desde España, también recogidos en la encuesta.

La población de referencia principal de los análisis que se llevan a cabo a partir de esta encuesta y en este trabajo en general son los españoles (nacidos en España especialmente) que han emigrado de nuestro país con edades comprendidas entre los 18 y 64 años en los primeros lustros del siglo actual y, sobre todo, a partir de 2008 (inicio de la crisis económica). El concepto de emigrante utilizado es el de migrante por largo plazo tal como ha sido definido por las Naciones Unidas y el Reglamento 862/2007 de la Unión Europea. ${ }^{5}$

Para el análisis de factores generales condicionantes e interpretación del fenómeno y su evolución se han utilizado, además de la bibliografía existente, las estadísticas de emigración española y otras de carácter social y económico que publican instituciones oficiales españolas e internacionales (fuentes secundarias). En este sentido, cabe destacar, por una parte, las estadísticas oficiales sobre flujos de emigración española que publica el INE (especialmente la EVR por ofrecer una serie

5 Las Naciones Unidas definen como migrante por largo plazo a "toda persona que se traslada de un país distinto de aquél en el que tiene su residencia habitual por un período de por lo menos un año" (Naciones Unidas, 1998, p. 10). El Reglamento CE n 862/2007 define como emigrante a aquella "persona, que habiendo sido previamente residente habitual en el territorio de un Estado miembro, deja de tener su residencia habitual en ese Estado miembro por un período que es, o se espera que sea, de al menos doce meses" (2007, p. 24). 
continuada desde 2002). Aún teniendo en cuenta sus limitaciones, constituyen las únicas de carácter oficial disponibles que ofrecen datos y cifras sobre el conjunto de la emigración española. Por otra, se han utilizado datos procedentes de fuentes estadísticas diversas, nacionales (INE, Turespaña, MINECO, MEySS, etc.) e internacionales (Eurostat, OCDE, etc.) que publican indicadores y series temporales de los mismos sobre la realidad social y económica de España (tasa de desempleo, renta per cápita, entre otras).

\section{Razones y motivos para emigrar. la incidencia de la crisis económica}

Los datos obtenidos a través de la encuesta ponen de relieve la existencia de motivaciones diversas entre los emigrados españoles para trasladar su residencia desde España a otro país. Estos motivos y su propio peso específico en la decisión de emigrar ofrecen, no obstante, variaciones significativas en función del año/período de salida de España (Tabla 1). Estas variaciones se relacionan, sin duda, con los distintos factores condicionantes de este fenómeno y su acción desigual y diferenciada a lo largo del tiempo.

Tabla 1. Principal motivo para emigrar desde España, 2001-2012.

\section{Porcentaje del total de emigrados en cada período}

\begin{tabular}{|l|r|r|r|r|}
\hline Motivo para emigrar desde España & $2001-2004$ & $2005-2007$ & $2008-2010$ & $2011-2012$ \\
\hline Estar sin empleo / falta de oportunidades laborales & 11,3 & 5,8 & 15,0 & 28,9 \\
\hline Mejorar situación laboral y/o económica & 14,8 & 15,3 & 17,9 & 15,6 \\
\hline Destino laboral & 4,7 & 11,6 & 10,6 & 9,2 \\
\hline Investigación y cooperación & 12,1 & 10,9 & 12,4 & 10,0 \\
\hline Estudios y formación & 8,6 & 9,1 & 10,0 & 11,7 \\
\hline Aprendizaje de idiomas & 21,9 & 11,6 & 10,9 & 7,7 \\
\hline Familiares y/o de pareja & 20,7 & 27,3 & 20,2 & 12,7 \\
\hline Otros motivos & 5,9 & 8,4 & 3,0 & 4,2 \\
\hline Total & 100,0 & 100,0 & 100,0 & 100,0 \\
\hline
\end{tabular}

Fuente: elaboración propia. Encuesta sobre la situación de los españoles en el extranjero 2012

Entre los emigrados durante el período 2001-2007, predominan los motivos de carácter no laboral: especialmente los formativos y familiares y/o de pareja, pero también otros de carácter más personal. Algo más del 55 \% de los encuestados que emigraron en dicho período aduce alguno de estos motivos como principal razón para su salida de España.

Entre quienes emigran desde mediados de la primera década del siglo actual se observa, no obstante, un paulatino crecimiento de los motivos de naturaleza laboral y/o económica, los cuales se convierten en mayoritarios a partir de 2008 y, sobre todo, 2011. Entre los emigrados en el trienio 2005-2007 los motivos esgrimidos en este sentido se relacionan principalmente con expatriaciones laborales (destino laboral de empresa o institución pública, cooperación, contratos 
de investigación) y mejores posibilidades de desarrollo profesional. Este patrón se mantiene entre los emigrados en el trienio 2008-2010. La prevalencia de estos motivos en la emigración que se desarrolla en estos años queda claramente reflejados en la legislación sobre el particular que se genera en estos años (Estatuto de la Ciudadanía Española en el Exterior, etc.) y en los pocos trabajos que se ocupan de este fenómeno (Valero et al., 2010; Alaminos et al., 2010; Alaminos y Santacreu, 2010).

Probablemente lo más relevante, en todo caso, es el peso creciente que experimenta entre quienes emigran a partir de 2008 motivos relacionados directamente con la falta de empleo y de oportunidades laborales. Este tipo de motivos pasa de ser la principal razón de salida de España para solo poco más de un $5 \%$ de los encuestados que emigran en el trienio 2005-2007, al $15 \%$ entre los que lo hacen en 2008-2010. Entre quienes emigran desde el año 2011 este tipo de motivos se convierte, con diferencia, en el más esgrimido como principal razón de salida del país (cerca del $25 \%$ en 2011 y del $40 \%$ en 2012).

La pregunta efectuada en la encuesta a las personas que habían emigrado de España a partir de 2008 sobre en qué medida había influido la crisis económica en su decisión de emigrar permite una aproximación más directa a la relación entre ambas variables. Los datos obtenidos son reveladores en este sentido (Figura 1).

Figura 1. Incidencia de la crisis económica en la decisión de emigrar, 2008-2012.

Datos relativos al total de emigrados en cada año

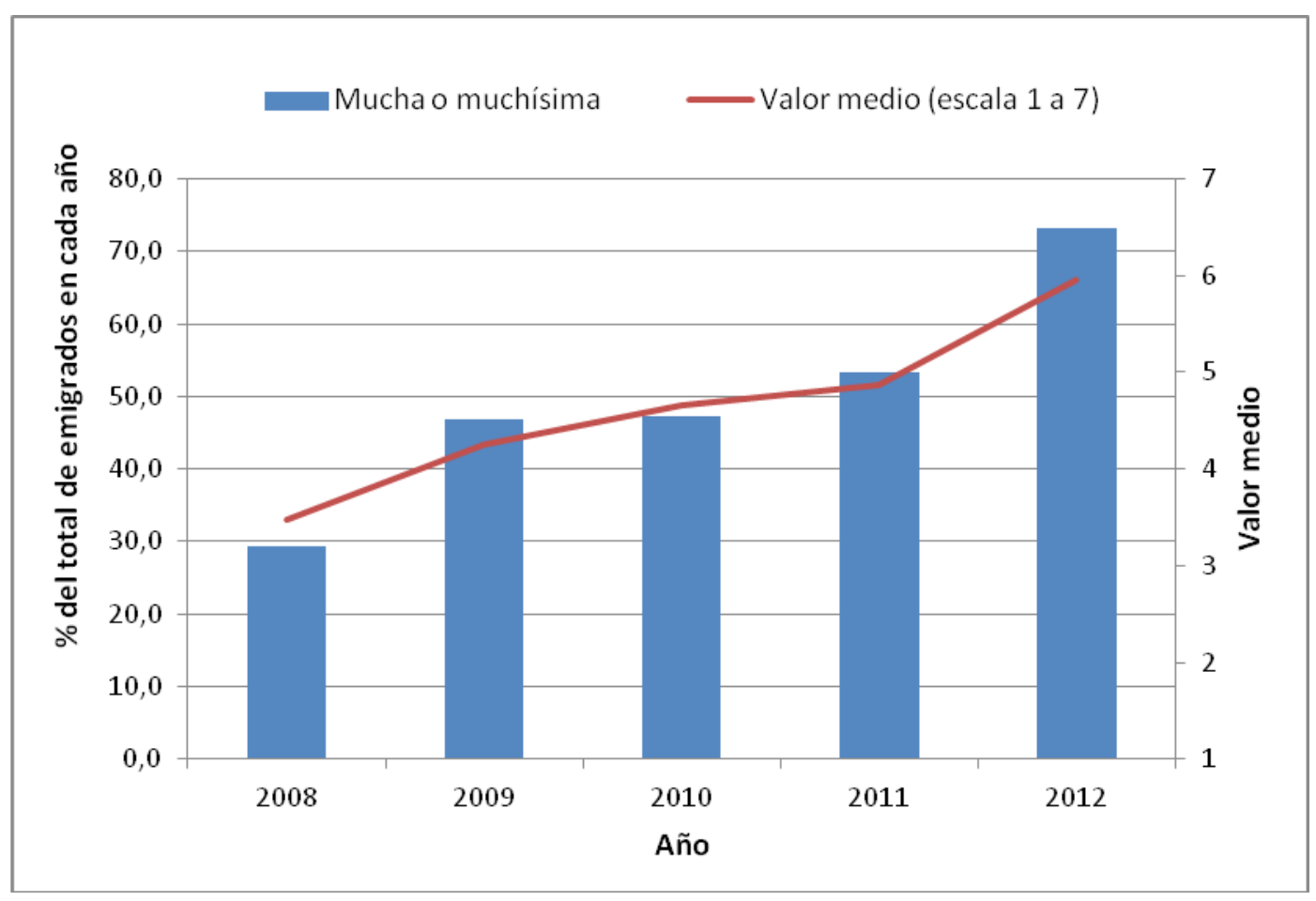

Fuente: elaboración propia. Encuesta sobre la situación de los españoles en el extranjero 2012 
La crisis económica ha tenido una elevada importancia (valores 6 y 7 de la escala 1-7) en la decisión de emigrar para algo más de la mitad de la población de referencia emigrada entre 2008 y 2012. Esta cifra se eleva hasta casi un $65 \%$ si se incluyen también las personas que manifiestan que ha tenido una destacada importancia (valor 5 de la escala). La proporción de personas que manifiestan que la crisis ha tenido una elevada importancia en su decisión de emigrar aumenta de forma clara en el período considerado, pasando de algo menos del 30 \% en 2008 a cerca del $75 \%$ en 2012. El valor medio muestra asimismo esta tendencia ascendente, así como el notable repunte experimentado en 2012.

\section{Factores condicionantes de la emigración y su evolución en el siglo actual}

Los datos anteriores sobre los motivos para emigrar desde España y la incidencia de la crisis en dicha decisión (fuentes primarias), puestos en relación con las estadísticas del flujo emigratorio y otras de carácter social y económico (fuentes secundarias), apuntan a una serie de factores generales como condicionantes del mismo y su evolución temporal.

En líneas generales, se pueden distinguir dos tipos o grupos de factores. Por una parte, los que favorecen la movilidad exterior, asociados a procesos de internacionalización de la sociedad y economía española en un contexto de creciente globalización. La salida de España se asocia, en este sentido, más a factores de atracción y vehiculares (relacionados con el incremento de las posibilidades de desplazamiento por razones diversas - reunificación familiar, redes y cadenas migratorias, accesibilidad y conectividad territorial, conocimiento del idioma, etc.-). Por otra, los que impulsan la emigración económico-laboral en su forma convencional, adaptada eso sí al actual contexto social de España (elevación de niveles de instrucción, etc.), asociados principalmente a factores de expulsión relacionados con la agudización de los efectos de la crisis económica (cierre de empresas, aumento tasa de desempleo, recortes en el gasto público, etc.).

\subsection{La emigración durante la primera década del siglo XXI: el crecimiento de la movilidad exterior}

Durante las últimas décadas del siglo XX y los primeros años del siglo XXI los datos e informaciones disponibles reflejan, respecto al período de emigración masiva anterior, una tendencia descendente en un contexto marcado en España por el impulso de la inmigración y de los retornos (RomeroValiente, 2003 y 2014; entre otros). Los datos de la encuesta realizada en 2012, correspondientes a españoles emigrados en este período, ponen de manifiesto que sus principales motivos para salir de España están relacionados con la familia/pareja y la mejora formativa.

Desde 2005, tanto los datos de las estadísticas españolas como de los países de destino (RomeroValiente, 2018), reflejan un cambio de tendencia en el flujo emigratorio, asistiéndose a un crecimiento sostenido e ininterrumpido del número de españoles que sale de nuestro país y fija su 
residencia en el extranjero. Entre las personas que salen de España en el segundo lustro del siglo actual se incrementa sensiblemente el peso como principal causa de emigración de los motivos relacionados con la expatriación (destino laboral, cooperación, investigación). Uno de cada cuatro emigrados entre 2005 y 2009 indica este tipo de motivos. Estos motivos, junto con aquellos también relacionados más o menos directamente con la movilidad exterior, como son la mejora formativa, las relaciones familiares y otros de carácter más personal, constituyen en conjunto la principal causa de emigración para al menos dos de cada tres personas que salen de España hasta 2009 (y casi el $60 \%$ hasta 2010).

El hecho de que ello se produzca en un momento en el que España goza probablemente de sus mayores niveles de bienestar de toda la historia, con tasas de desempleo que se reducen de forma importante alcanzando niveles mínimos de las últimas décadas, no se podría explicar suficientemente sin tener en cuenta la concurrencia en el tiempo de una serie de factores sociales y económicos. Entre ellos cabe destacar, entre otros, los siguientes:

- El incremento de la renta personal disponible y la existencia de excedentes pecuniarios que permiten el incremento de los desplazamientos y estancias fuera de España, favorecidos además por las facilidades crediticias (préstamos fáciles y a relativamente bajo interés) y la fortaleza del euro en relación al dólar. Los datos sobre la evolución de la renta per cápita en España entre 2001 y 2013 (Figura 2) ponen en evidencia este crecimiento que alcanza sus máximos absolutos, con seguridad los mayores de toda la historia de nuestro país, en los años 2007 y 2008. Sirva también como dato que el número de viajes al extranjero realizados por los españoles prácticamente se duplica durante la primera década del siglo XXI pasando de algo menos de siete millones al principio de la misma a más de doce en 2010 (Figura 2). El mayor crecimiento se registra a partir de 2004, situándose desde 2005 siempre por encima de los diez millones.

- La internacionalización de la sociedad española, favorecida especialmente por la llegada masiva de inmigrantes a nuestro país y el crecimiento constante de los intercambios en el ámbito de la educación (especialmente la superior a través de programas de movilidad académica como Erasmus). Estos contactos, relaciones y experiencias con personas de otros países, así como las estancias temporales en el extranjero son, en no pocos casos, el germen de parejas mixtas y familias trasnacionales (Roca et al., 2012; Steingress, 2012), y la base de cambios de residencia al exterior. 
Figura 2. PIB per cápita en España y número de viajes de los españoles al extranjero, 2001-2013

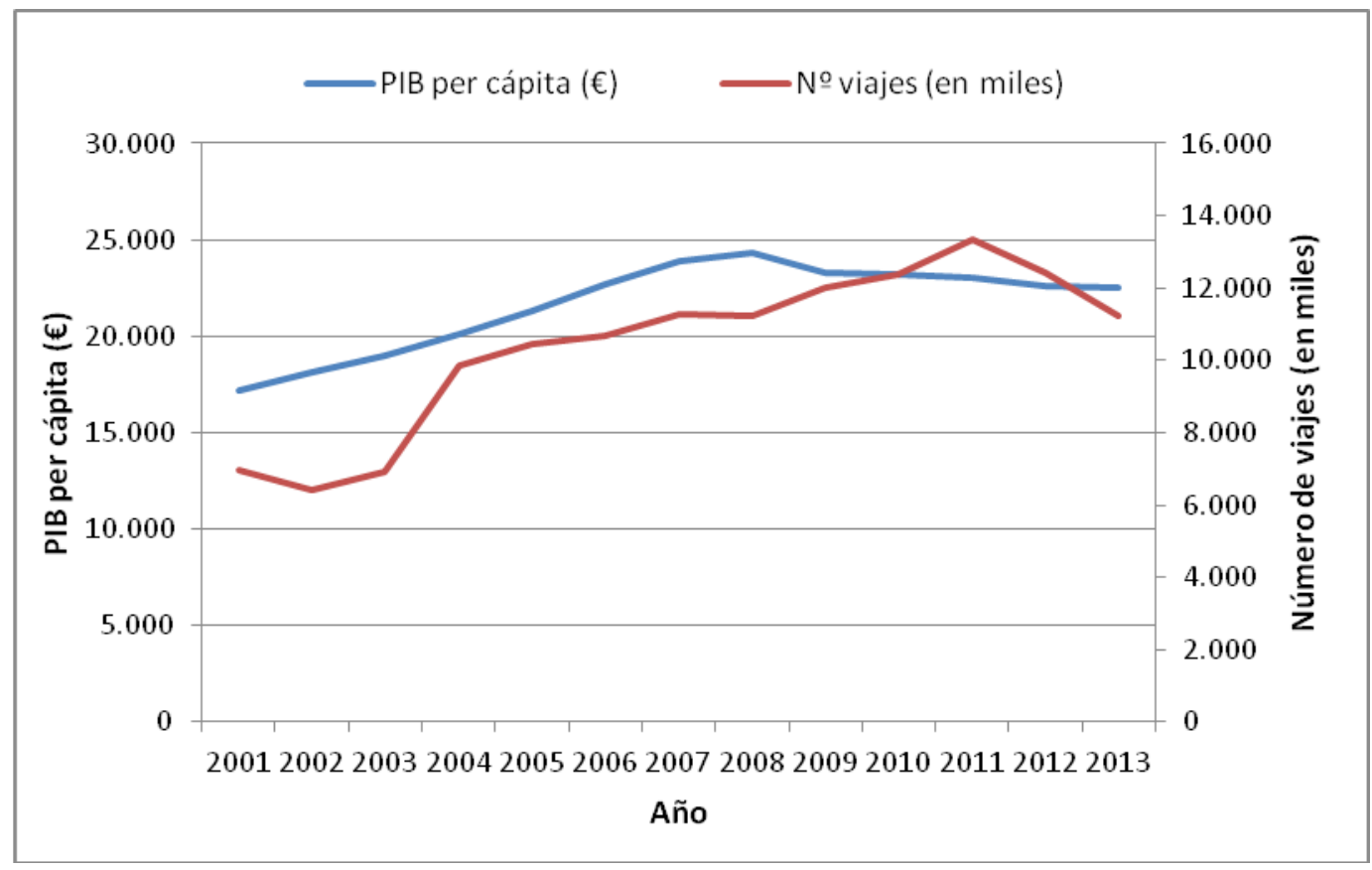

Fuente: elaboración propia a partir de Eurostat (banco de datos) y Turespaña

- La internacionalización de la economía y las empresas españolas (Marca España, 2013). Ello se relaciona en buena medida con el incremento de la inversión española en el exterior (Menéndez y Méndez, 2011), la cual alcanza sus máximas magnitudes en los años 2006 y, sobre todo, 2007 (Figura 3). El proceso de internacionalización de las empresas españolas se hace incluso aún más evidente en los últimos años de la década, coincidiendo con el inicio de la crisis económica, por la imperiosa necesidad de reorientar muchas de sus actividades y negocios hacia el exterior (Ortega, 2010).

- El incremento de la presencia de España en la esfera internacional a través de la potenciación de su acción pública en el exterior (ayuda oficial al desarrollo, representación diplomática, misiones humanitarias y de seguridad, participación en proyectos internacionales, etc.). Ello se produce tanto a nivel estatal como a través de comunidades autónomas y entidades locales que incrementan su protagonismo en este sentido de acuerdo a sus competencias y en virtud del aumento de sus disponibilidades presupuestarias. La evolución del gasto de España en Ayuda Oficial al Desarrollo entre 2001 y 2013 (Figura 3) nos ofrece una clara idea sobre el particular. Como se puede observar, el crecimiento es constante hasta el año 2008, en que alcanza su máximo histórico, produciéndose un descenso en los años subsiguientes. En los años 2009 y 2010 el gasto sigue siendo aún elevado (muy por encima incluso del año 2007), produciéndose a partir de 2011, pero sobre todo 2012, un brusco descenso que lo sitúa en niveles anteriores a 2001. 
Figura 3. Inversión española en el extranjero (IEE)

y gasto en Ayuda Oficial al Desarrollo (AOD), 2001-2013

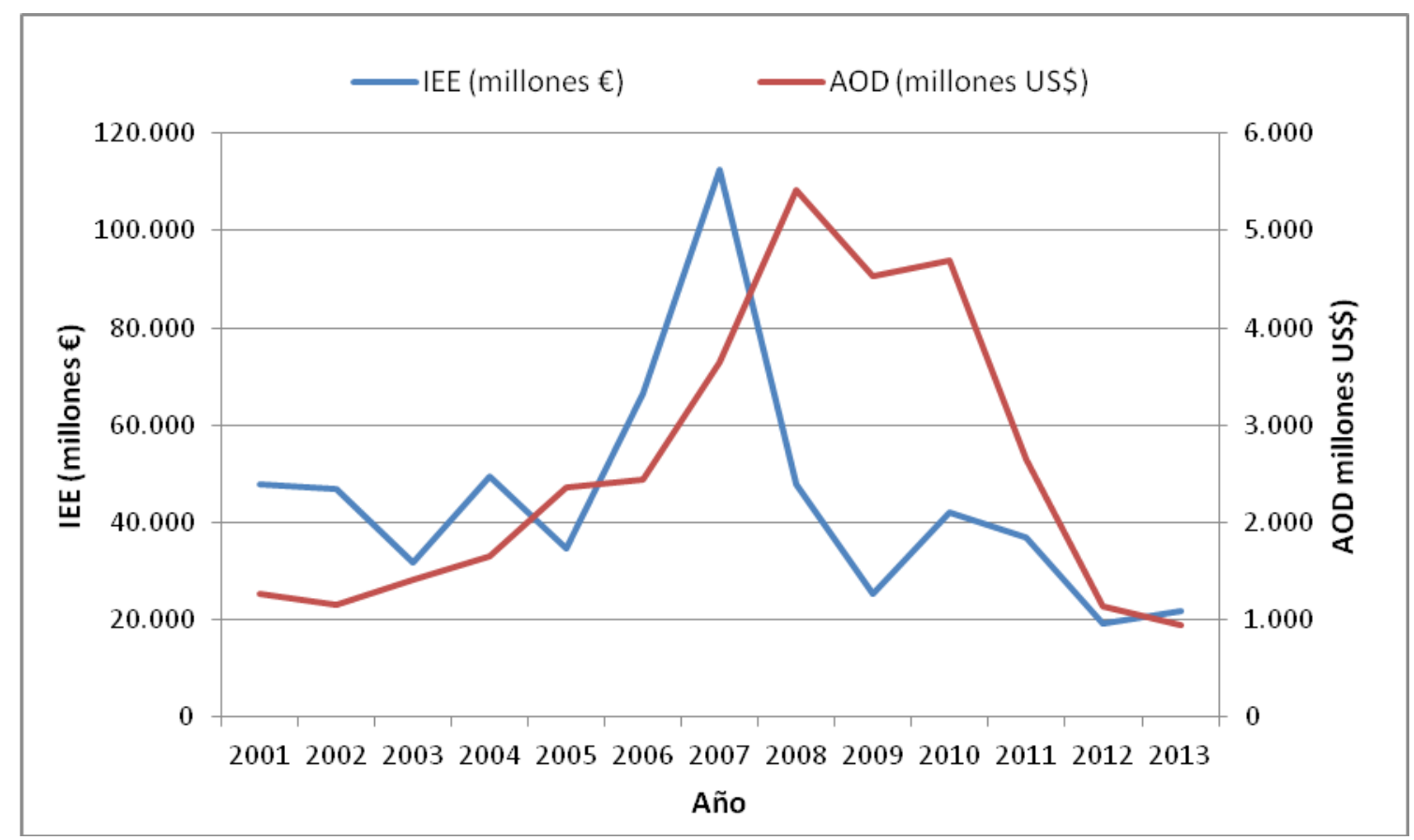

Fuente: elaboración propia a partir de Secretaría de Estado de Comercio (MINECO)

y OCDE (banco de datos estadísticos)

De este modo, la notable acentuación de los procesos de internacionalización de la sociedad y economía españolas (en un contexto de globalización), así como el incremento elevado de la presencia y acción exterior de nuestro país, favorecen durante el segundo lustro del siglo actual un aumento de la movilidad exterior. Algo que, por otra parte, también se verifica en otros países de Europa y del mundo desarrollado que viven una situación, con sus singularidades, relativamente parecida.

\subsection{El impulso de emigración en la segunda década del siglo actual: la agudización de los efectos de la crisis económica.}

Los datos de las estadísticas oficiales españolas indican que el número de emigrantes españoles se mantiene prácticamente estable en 2008 y 2009, incrementándose ligeramente en 2010. Es en 2011 cuando se evidencia un mayor crecimiento de la emigración, la cual ha seguido creciendo en términos absolutos de forma sostenida en los años siguientes (2012-2015), aunque a un ritmo algo inferior.

La crisis económica, iniciada en 2008, se hace sentir desde el primer momento en forma de descenso acusado de la actividad económica y destrucción de empleo. La tasa de paro se multiplica por dos entre 2007 y 2009, pasando, según datos de Eurostat, del 7,1\% al 15,2\% entre la población nacida en España entre 20 y 64 años (Figura 4). Para la población entre 25 y 
29 años, en la que se registran los mayores niveles de emigración tanto en términos absolutos como relativos (Romero-Valiente, 2016, 2017a, 2018), la tasa de desempleo pasa del 8,7\% en 2007 al 20,3\% en 2009.

Figura 4. Flujo emigratorio y tasa de paro de la población española (nacidos en España), 2001-2013

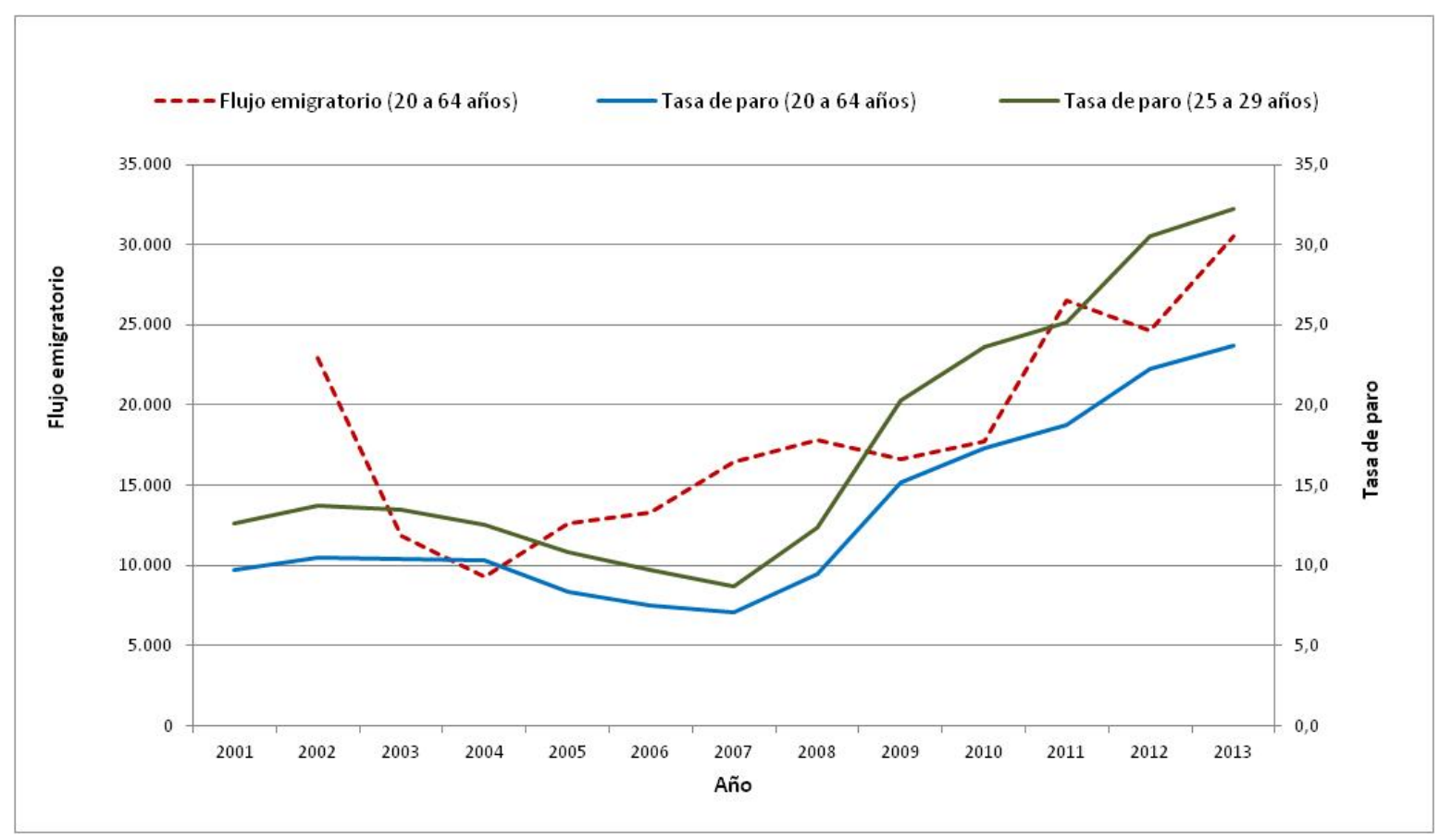

Fuente: elaboración propia a partir de EVR-INE (microdatos) y Eurostat (bases de datos)

La crisis, sin embargo, no hace mella de forma inmediata en el crecimiento de la emigración. La explicación de ello parece estar relacionada con el mantenimiento a niveles elevados del gasto público (e incluso incremento de forma de tratamiento de choque con planes intensivos de empleo como el Plan de Economía Sostenible -Plan E-), así como el papel amortiguador jugados por el colchón familiar, las prestaciones por desempleo y otras ayudas sociales. Sirva como dato que el número de altas iniciales de beneficiarios de prestaciones por desempleo se dispara fundamentalmente en estos primeros años de la crisis, pasando de 1,5 millones en 2007 a 2,5 en 2009 en el caso de las de carácter contributivo, y de 0,4 millones en 2007 a 1,6 en 2010 en las de tipo asistencial (Figura 5). 
Figura 5. Número de beneficiarios de prestaciones

por desempleo en España según tipología, 2005-2013

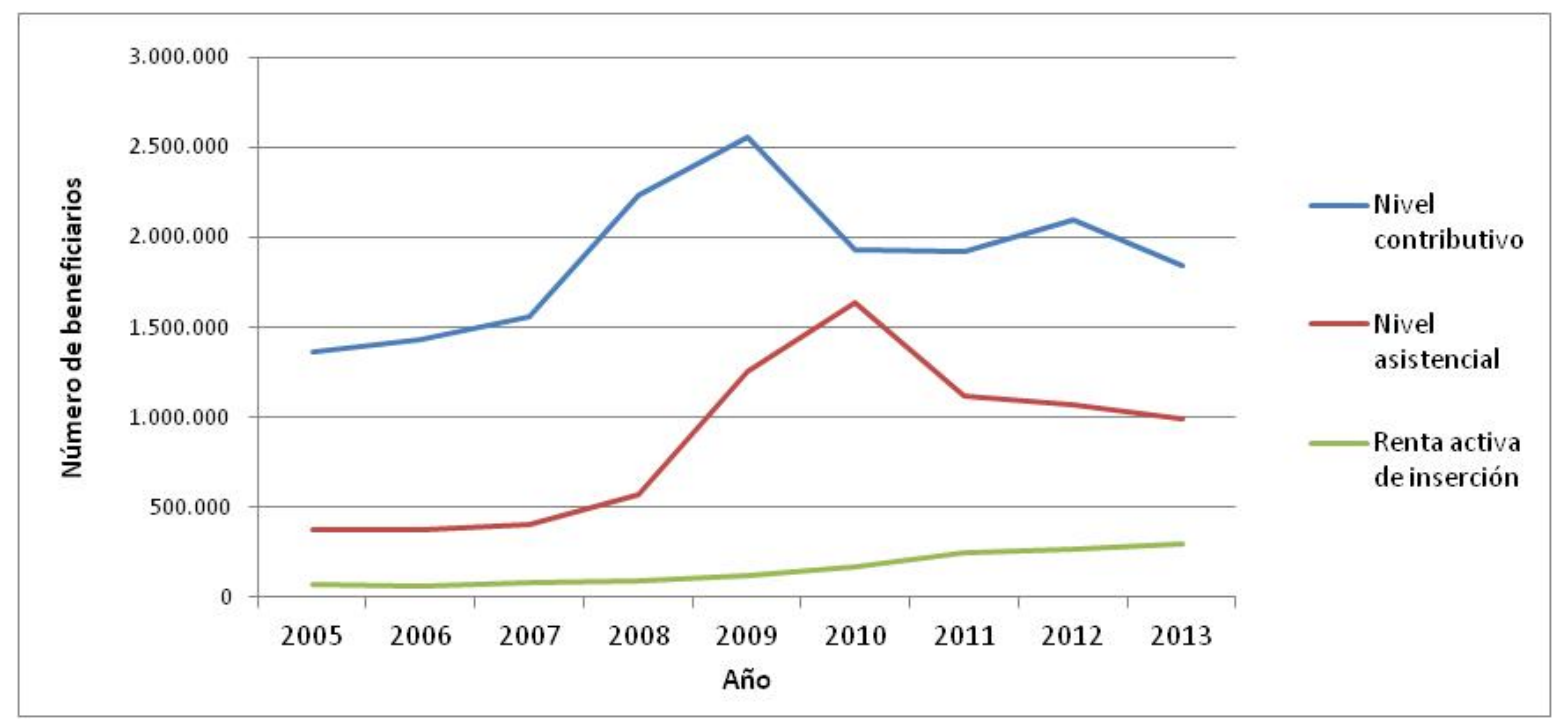

Fuente: elaboración propia a partir del Ministerio de Empleo

y Seguridad Social (MeySS) (bases de datos)

A partir de 2010 y, especialmente, 2011, la agudización de los efectos de la crisis económica y la falta de expectativas laborales (continua precarización del mercado de trabajo, recortes de empleo público, etc.) han acabado por elevar, hasta niveles no conocidos desde mediados de la década de los 70 del siglo XX, la emigración española hacia el exterior. El progresivo agotamiento del colchón familiar y de las prestaciones por desempleo ha jugado, en muchos casos, a favor de ello. La emigración se ha visto facilitada además, en algunos casos, por la propia reorientación de las empresas españolas hacia el exterior (especialmente en sectores como la construcción y determinados servicios) y las actuaciones de atracción operadas desde diversos países que demandan profesionales en ámbitos específicos (Alemania en el de la ingeniería; Reino Unido y países nórdicos en el de la sanidad; Ecuador en el de la educación; etc.).

Estos efectos de la crisis han sido el detonante de la emigración especialmente para varias decenas de miles de jóvenes con una formación elevada obtenida en años precedentes (los de mayor incremento absoluto y relativo del número de titulados universitarios en España), que se encuentran ante un mercado laboral incapaz de absorberlos y satisfacer sus expectativas, el cual además se constriñe continuamente. ${ }^{6}$ Sirva como dało que, según Eurostat, en 2013 había cerca de 1,2 millones de personas (entre 25 y 64 años) con titulación superior en España en situación de

6 El propio Real Decreto-ley 3/2012, de medidas urgentes para la reforma del mercado laboral (BOE núm. 36, 11 de febrero de 2012) reconoce en su exposición de motivos esta situación: "La gravedad de la crisis actual no tiene precedentes. (...) La incertidumbre a la hora de entrar en el mercado de trabajo, los reducidos sueldos iniciales y la situación económica general están provocando que muchos jóvenes bien formados abandonen el mercado de trabajo español y busquen oportunidades en el extranjero." 
desempleo, la cifra más elevada con diferencia de la serie estadística (Figura 6). Dicha cifra, en constante crecimiento desde 2008, supone casi cuatro veces más que en 2007, año inmediatamente anterior al inicio de la crisis.

Figura 6. Flujo emigratorio de españoles y stock de titulados superiores sin empleo en España (personas entre 25 y 64 años), 2001-2013

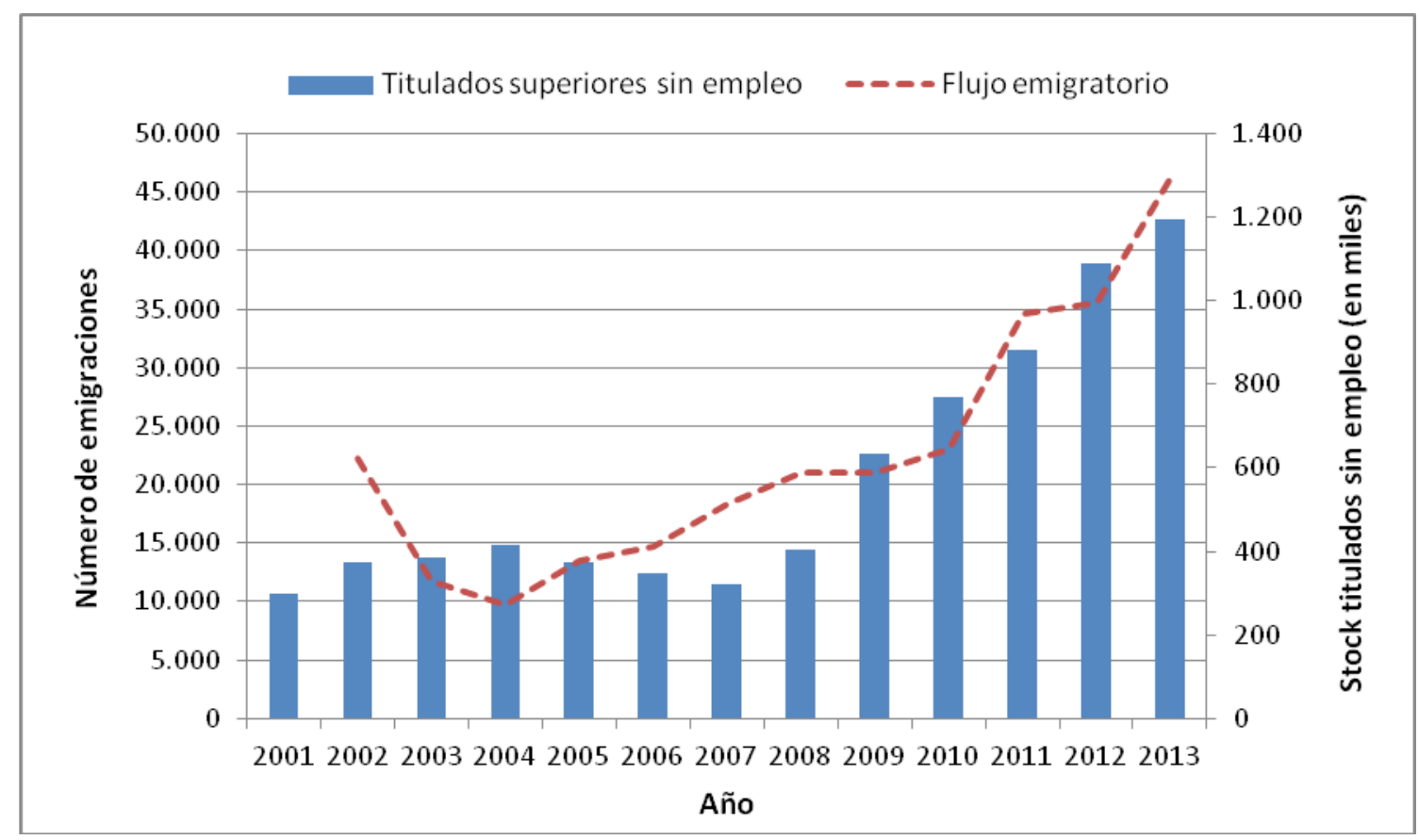

Fuente: elaboración propia a partir de EVR-INE (microdatos) y Eurostat (bases de datos)

La reducción en los últimos años de la inversión española en I+D o del número de profesores (en todos los niveles educativos, pero especialmente en el ámbito universitario), así como el aumento de las condiciones de precariedad laboral de los mismos, constituyen solo otros más de los innumerables efectos de la crisis económica y las políticas de austeridad que, sin duda, han favorecido el crecimiento de la emigración.

Los datos obtenidos en la encuesta realizada en 2012 vienen a avalar esta explicación. Aunque los motivos relacionados con la búsqueda de empleo y la falta de oportunidades laborales, así como la incidencia de la crisis en la decisión de emigrar, crecen progresivamente entre los emigrados desde 2008, no se convierten en mayoritarios hasta los que lo hacen a partir de 2011. Más del 50 \% de los emigrados en 2011 y del 70 \% en 2012 manifiesta que la crisis económica ha tenido mucha o muchísima importancia en su decisión de emigrar.

Para los años más recientes (2013-2015) no se dispone de datos de la amplitud y consistencia de los recogidos en la encuesta para conocer más correctamente los motivos de la emigración española durante los mismos. No obstante, la relación verificada para los años inmediatamente precedentes entre los factores asociados a la crisis económica y el crecimiento de la emigración, 
inducen a pensar que los motivos relacionados con la búsqueda de empleo y la falta de oportunidades laborales han seguido constituyendo la principal causa de salida de nuestro país. Las entrevistas que venimos realizando a españoles que han emigrado en estos últimos años apuntan en este sentido, ya que la crisis económica y los motivos laborales siguen constituyendo la principal causa de salida de España (Rodríguez et al., 2015a, 2015b, 2016a, 2016b, 2017). Otros trabajos realizados en los últimos años (INJUVE, 2013; OIM, 2014), en los que se han llevado a cabo encuestas y entrevistas a emigrados españoles, también se expresan en parte en esta línea.

Aunque la tasa de desempleo ha descendido algo en estos dos últimos años (2014-2015), el número de emigrados ha podido seguir creciendo debido a la acumulación de personas activas sin empleo (especialmente adultos-jóvenes con estudios de grado superior), así como a la propia capacidad de autosustentación del proceso. La evolución del flujo emigratorio parece guardar tanta o más estrecha relación con la acumulación de titulados sin empleo (especialmente superiores) que con la de la tasa de desempleo. Así parece que, al menos por acumulación de activos e inercia del proceso, que se retroalimenta por el efecto difusión de los medios de comunicación y los propios emigrados (redes sociales y cadenas migratorias), es probable que la emigración aún seguirá manteniéndose a niveles relativamente importantes en los próximos años.

La emigración más asociada a la "movilidad exterior", con sus singulares características y perfiles, impulsada en menor medida por factores de expulsión de carácter laboral/económico, sigue teniendo relevancia en el proceso, pero ha pasado a ocupar un segundo plano en el mismo. Ha sido opacada, al menos en parte, por el resurgir, tras casi 35 años, de una emigración de corte genuinamente económico conformada por personas que se ven expulsadas por motivos laborales/económicos en busca de oportunidades y medios propios de vida, de un futuro mejor acorde a sus expectativas.

\section{Conclusiones}

Este trabajo constituye una contribución al conocimiento de las causas de la emigración española en el siglo actual, especialmente la que se viene desarrollando desde 2008 al socaire de la crisis económica. Particularmente, aporta datos y análisis al debate existente sobre el peso que ejercen en este fenómeno los factores y motivaciones relacionadas con la denominada "movilidad exterior" y los asociados a los efectos de la crisis económica. Los análisis llevados a cabo, siguiendo una metodología mixta y triangular, a partir de datos procedentes de fuentes primarias (encuesta a emigrantes) y secundarias (series estadísticas de emigración, indicadores sociales y agregados macroeconómicos en España), permiten extraer las siguientes conclusiones.

Los factores que favorecen la movilidad exterior, asociados a procesos de internacionalización de la sociedad y economía española, en un contexto de bonanza económica y creciente globalización 
(incremento de los contactos con personas de otras nacionalidades, aumento del gasto público y potenciación de la acción exterior, etc.), constituyen los principales responsables del flujo emigratorio durante la primera década del siglo actual hasta prácticamente el final de la misma. Buena prueba de ello es el marcado protagonismo que tienen entre los emigrados durante este período los motivos relacionados con la expatriación laboral (desplazados por empresas e instituciones públicas, cooperación, etc.), los estudios y la formación, así como los familiares y otros de carácter más personal. La mayoría de las personas que emigran de España durante este período lo hacen principalmente por factores de atracción asociados a mejores posibilidades de crecimiento profesional y/o personal en los países de destino. La emigración de españoles, aunque con una tendencia creciente desde 2005, presenta todavía, no obstante, hasta finales de esta década cifras modestas.

Desde 2008, pero sobre todo a partir de 2011, la emigración española experimenta un notable repunte alcanzando desde el inicio de la segunda década del siglo actual cifras que no se registraban desde los años 70 del siglo XX. Aunque los factores anteriormente descritos, relacionados con la movilidad exterior, siguen jugando un papel importante en este proceso (particularmente entre 2008 y 2010), este repunte se debe fundamentalmente a la entrada en escena de un nuevo actor, la crisis económica, con sus efectos en forma de incremento del desempleo y reducción de las oportunidades laborales. La progresiva agudización de estos efectos a medida que se hace más crónica la crisis, se reduce el gasto público (política de recortes y austeridad) y se agotan los colchones social (prestaciones y subsidios) y familiar, han contribuido a que este fenómeno haya seguido creciendo en los últimos años.

En este período, los factores típicamente de expulsión se convierten en los principales protagonistas del proceso, provocando la emigración desde España de un gran número de personas que no tenían entre sus planes de futuro la intención de hacerlo. El elevado stock, e incremento constante, de profesionales y titulados (especialmente universitarios) en situación de desempleo (y escasas esperanzas de encontrarlo y de desarrollo profesional) constituye muy posiblemente el principal caladero de esta nueva emigración. Asimismo, es uno de los factores que mejor explica el crecimiento continuo de la emigración en los últimos años (2014 y 2015) a pesar de la evolución positiva experimentada por algunos indicadores socioeconómicos (crecimiento del PIB, reducción de la tasa de desempleo).

Entre las principales aportaciones, a nuestro juicio, de este trabajo cabe destacar que dimensiona y relativiza el peso de los distintos factores en la evolución y crecimiento de la emigración española en el siglo actual. Y corrobora, con evidencias empíricas, la importante incidencia que está teniendo la crisis económica y sus efectos asociados (aumento del desempleo, etc.) en el repunte del flujo emigratorio, especialmente desde 2011, actuando claramente como factor de expulsión. Este trabajo pone de relieve, también, no obstante, la importancia en el crecimiento de la 
emigración de factores de carácter más estructural relacionados con el incremento de la movilidad internacional, presentes por otra parte en la gran mayoría de los países de su entorno europeo y desarrollados en general. Estos factores son predominantes hasta el estallido de la crisis, conviviendo con los de expulsión en el flujo que se desarrolla durante los primeros años de la misma (2008-2010) y, de forma más matizada, entre 2011 y 2015. Es muy probable que, una vez remitan los efectos de la crisis, estos últimos factores vuelvan a ganar protagonismo en el proceso emigratorio, coadyuvando al sostenimiento del mismo. La crisis económica, en cualquier caso, habrá contribuido a activar y precipitar la emigración de miles de españoles, muchos de los cuales pasaran a engrosar la legión de "free movers" que participan en procesos de migración circular y reemigración a terceros países. 


\section{Bibliografía}

Alaminos, A., Albert, M. C., y Santacreu, O. (2010). La movilidad social de los emigrantes españoles en Europa. Revista Española de Investigaciones Sociológicas, 129, 13-15.

Alaminos, A., y Santacreu, O. (2010). La emigración cualificada española en Francia y Alemania. Papers, 95(1), 201-211.

Alarcón, E., y Fernández, J. A. (2015). Informe sobre emigració i població barcelonina resident a I'estranger. Barcelona: Consell Econòmic i Social de Barcelona (CESB).

Alba, S., Fernández, A., y Martínez, U. (2013). Crisis económica y nuevo panorama migratorio en España. Madrid: Fundación $1^{\circ}$ de mayo.

Alba, S., y Fernández, A. (2015). Nueva emigración exterior y cuestión laboral. Informe 2014. Madrid: Fundación $1^{\circ}$ de mayo.

Alonso, J. A. (2006). Factores explicativos de la emigración. Ponencia presentada en el / Congreso Internacional sobre Desarrollo Humano. Madrid.

Alonso, J. A. (2011). Tiempo de emigración: factores, prejuicios y consecuencias. Documentación Social, $147,11-25$.

Arango, J. (2003). La explicación teórica de las migraciones: luz y sombra. Migración y Desarrollo, $1(1), 1-30$.

Arango, J. (2016). Spain: New Emigration Policies Needed for an Emerging Diaspora. Washington, D.C.: Transatlantic Council on Migration y Migration Policy Institute.

Barbulescu, R., Bermúdez, A., y Brey, E. (2015). Vente para Europa, Pepe? La nueva emigración desde España en tiempos de crisis económica. Panorama Social, 22, 127-138.

Beer, J., Raymer, J., Erf., R., y Wissen, L. (2010). Overcoming the Problems of Inconsistent International Migration data: A New Method Applied to Flows in Europe. European Journal of Population, 26(4), 459-481.

Biacabe, J., y Robert, S. (2014). Les Français de l'étranger. La expatriation des Français, quelle réalité. Paris: Chambre de commerce et díndustrie de región Paris e Île de France.

Cantor, G. (2002). La Triangulación Metodológica en Ciencias Sociales. Cinta de Moebio, 13. Recuperado de http://www2.facso.uchile.cl/publicaciones/moebio/13/cantor.htm

Castles, S., Haas, H. de, y Miller, M. J. (2014). The Age of Migration. International Population Movements in the Modern World (5. ${ }^{a}$ ed.). Basingstoke: Palgrave Macmillan. 
De Marco, S., y Sorando, D. (2015a). Juventud Necesaria. Consecuencias económicas y sociales de la situación del colectivo joven. Recuperado de http://www.cjb.cat/noclaudiquis/wpcontent/uploads/sites/2/2015/09/JUVENTUD-NECESARIA-Informe-completo.pdf

De Marco, S., y Sorando, D. (2015b). Juventud Necesaria. Consecuencias económicas y sociales de la situación de la Juventud en Navarra. Recuperado de http://www.navarra.es/NR/rdonlyres/16293338-DC92-4D37-AEF7-

B3631A2A4CE8/347429/JN_Navarra.pdf

Díaz-Hernández, R., Domínguez-Mújica, J., y Parreño-Castellano, J. (2015). Una aproximación a la emigración española durante la crisis económica: herramientas de estudio. Ar@cne, 198. Recuperado de http://www.ub.edu/geocrit/aracne/aracne-198.pdf

Domingo, A., y Sabater, A. (2013). Crisis económica y emigración: la perspectiva demográfica. En E. Aja, J. Arango y J. Oliver (Eds.), Inmigración y crisis: entre la continuidad y el cambio. Anuario de la Inmigración en España 2012 (pp. 61-87). Barcelona: CIDOB.

Domingo, A., Sabater, A., y Ortega-Rivera, E. (2014). ¿Migración neohispánica? El impacto de la crisis económica en la emigración española. Empiria, 29, 39-66.

Domingo, A., y Blanes, A. (2015). Inmigración y emigración en España: estado de la cuestión y perspectivas de futuro. En J. Arango, D. Moya, J. Oliver y E. Sánchez-Montijano (Eds.), Flujos cambiantes, atonía institucional. Anuario de la Inmigración en España 2014 (pp. 94-122). Barcelona: CIDOB.

Domingo, A., y Ortega-Rivera, E. (2015). La emigración española. Esa vieja desconocida. En C. Torres (Ed.), España 2015. Situación social (pp. 207-215). Madrid: Centro de Investigaciones Sociológicas.

Ebanks, E. G. (1993). Determinantes socioeconómicos de la migración interna, con especial referencia a la región de América Latina y el Caribe. Serie E, N³8 (LC/DEM/G. 143). Santiago de Chile: Centro Latinoamericano de Demografía (CELADE).

Faraco, C., Castillo, E., Krausslach, M., y Montero, M. (2013). Proyecto nueva emigración. Informe Final. Coordinadora Federal del Movimiento Asociativo en la RFA. Recuperado de http://www.iree.org/mediapool/132/1325651/data/PNM_Informe_final_30.9_1_.pdf

Fernández de Pinedo, E. (1988). Los movimientos migratorios vascos, en especial hacia América. En Sánchez Albornoz, N. (comp.) Españoles hacia América. La emigración en masa, 1880-1930 (pp. 105-122). Madrid: Alianza Editorial.

García Abad, R. (2003). Un estado de la cuestión de las teorías de las migraciones. Historia Contemporánea, 26, 329-351. 
Gil, A. y Fernández, M. J. (2015). Los discursos sobre la emigración española en perspectiva comparada. Principios del siglo XX-principios del siglo XXI (Documentos de Trabajo IELAT, n. ${ }^{\circ}$ 73). Instituto de Estudios Latinoamericanos y Universidad de Alcalá. Recuperado de http://ielat.com/inicio/index.php/publicaciones/documentos-de-trabajo-blog/1538-el-ielatpublica-el-dt-73-los-discursos-sobre-la-emigracion-espanola-en-perspectiva-comparada-principios-delsiglo-xx-principios-del-siglo-xxi

Glynn, I., Kelly, T., y Macéinrí, P. (2013). Irish Emigration in an Age of Austerity. Cork: University College Cork.

González Enríquez, C. (2013). ¿ Emigran los españoles? ARI 39/2013. Madrid: Real Instituto Elcano. Recuperado de http://www.realinstitutoelcano.org/wps/portal/rielcano/contenido?WCM_GLOBAL_CONTEXT= /elcano/elcano_es/zonas_es/ari39-2013-gonzalez-enriquez-emigran-los-espanoles

González, C., y Martínez, J. P. (2014). Country Focus: Migration of Spanish nationals during the crisis. Madrid: Real Instituto Elcano. Recuperado de http://www.realinstitutoelcano.org/wps/portal/web/rielcano_en/contenido?WCM_GLOBAL_C ONTEXT=/elcano/elcano_in/zonas_in/demography+population/gonzalezenriquezmartinezromera-espana-emigracion-espanoles-crisis-spain-migration-crisis

González Ferrer, A. (2013). La nueva migración española. Lo que sabemos y lo que no. Zoom Político, n. 18. Madrid: Fundación Alternativas.

Hidalgo-Capitán, A. L. (2013). Las migraciones internacionales en el contexto de la globalización. Una explicación multicausal. En Romero-Valiente et al. (Eds.), Migraciones Iberoamericanas. Las migraciones España-Brasil (pp. 235-258). Huelva: Centro de Investigación en Migraciones y Universidad de Huelva.

INJUVE (2013). La emigración de los jóvenes españoles en el contexto de la crisis. Análisis y datos de un fenómeno difícil de cuantificar. Madrid: Observatorio de la Juventud en España.

Izquierdo, M., Jimeno, J. F., y Lacuesta, A. (2014a). Los flujos migratorios en España durante la crisis. Boletín económico, septiembre, 53-62.

Izquierdo, M., Jimeno, J. F., y Lacuesta, A. (2014b). La emigración de españoles durante la Gran Recesión (2008-2013). Cuadernos Económicos de ICE, 87, 223-240.

Jannuzzi, P. M. (2000). Tasas específicas por motivos y acompañantes de la migración: una contribución a la interpretación y al uso de modelos de patrones etarios de migración. Notas de población, 27(70), 33-85. 
Jennissen, R. (2003). Economic Determinants of Net International Migration in Western Europe. European Journal of Population, 19(2), 171-198.

Kaczmarczyk, P., y Stanek, M. (2016). Crisis and Beyond: Intra-EU Mobility of Polish and Spanish Migrants in a Comparative Perspective. En Triandafyllidou, A. y Isaakyan, I. (eds). High-Skill Migration and Recession. Gendered Perspectives (pp. 69-100). Reino Unido: Palgrave Macmillan.

Martínez Veiga, U. (2000). Teorías sobre las migraciones. Migraciones \& Exilios, 1, 11-26.

Marca España (2013). Presencia de España. La empresa española en el mundo. Madrid: Ministerio de Asuntos Exteriores y Cooperación. Recuperado de http://www.exteriores.gob.es/Portal/es/SalaDePrensa/Multimedia/Publicaciones/Documents/P RESENCIA\%20DE\%20ESPANA\%202013.pdf

Massey, D. S., Arango, J., Hugo, G., Kouaouci, A., Pellegrino, A., y Taylor, J. E. (1993). Theories of International Migration: A Review and Appraisal. Population and Development Review, 19(3), $431-466$

McAleer, M. C. (2013). Time to Go? A Qualitative Research Study Exploring the Experience \& Impact of Emigration on Ireland's Youth. Dublin: National Youth Council of Ireland. Recuperado de http://www.youth.ie/sites/youth.ie/files/NYCl_Youth_Emigration_Report.pdf

Menéndez, A., y Méndez, M. (2011). Evolución de las inversiones en el extranjero de las empresas no financieras españolas e implicaciones para su estructura financiera y rentabilidad. Boletín Económico del Banco de España, 12, 58-65.

Moldes, R. , y Gómez, F. (Eds.) (2015). ¿ Por qué te vas? Jóvenes españoles en Alemania. Madrid: Los Libros de la Catarata.

Murray, R., Hardong, D., Gillespie, R., y Arora, H., (2012). Emigration from the UK. Second Edition (Research Report 68, November 2012). Londres: Home Office.

Naciones Unidas (1998). Recommendations on Statistics of International Migration. Revision 1 (Statistical Papers Series M, n. ${ }^{\circ}$ 58, rev. 1). Nueva York: United Nations, Department of Economic and Social Affairs, Statistics Division.

OIM (2014). Aproximación a la Situación de los Españoles Emigrados: Realidad, Proyecto, Dificultades y Retos. Madrid: Organización Internacional para las Migraciones.

Ortega, A. (2010). La internacionalización de la empresa española y la decisión de exportar como solución a la crisis. Revista de la Facultad de Ciencias Sociales y Jurídicas de Elche, I(6), 88-111. Recuperado de http://revistasocialesyjuridicas.umh.es/Revista/NUMERO_6_files/O7-Ortega.pdf

Palazón, S. (1995). Capital humano español y desarrollo latinoamericano. Evolución, causas y características del flujo migratorio (1882-1990). Alicante: Instituto de Cultura Juan Gil-Albert. 
Palazón, S. (1998). Reanudación, apogeo y crisis de la emigración exterior española (1946-1995). Ería, 45, 37-53.

Poulain, M., y Dal, L. (2008). Estimation of flows within the intra-EU migration matrix. Report for the MIMOSA project. Recuperado de http://mimosa.cytise.be/Documents/Poulain_2008.pdf

Reglamento (CE) B 862/2007 del Parlamento Europeo y del Consejo de 11 de julio de 2007 sobre las estadísticas comunitarias en el ámbito de la migración y la protección internacional. Diario Oficial de la Unión Europea, 31 de julio de 2007, L 199.

Reques, P., y de Cos, O. (2003). La emigración olvidada: la diáspora española en la actualidad. Papeles de Geografía, 37, 199-216.

Roca, J., Soronellas, M., y Bodoque, Y. (2012). Migraciones por amor: diversidad y complejidad de las migraciones de mujeres. Papers, 97(3), 685-707.

Rodríguez-Fariñas, M. J., Romero-Valiente, J. M., e Hidalgo-Capitán, A. L. (2015a). Los exiliados económicos. La tercera oleada de emigración española a Chile. Revista de Geografía Norte Grande, 61, 107-133.

Rodríguez-Fariñas, M. J., Romero-Valiente, J. M., e Hidalgo-Capitán, A. L. (2015b). Los exiliados económicos. La nueva emigración española a Ecuador. OBETS, 10(2), 397-435.

Rodríguez-Fariñas, M. J., Romero-Valiente, J. M., e Hidalgo-Capitán, A. L. (2016a). Los exiliados económicos. La nueva emigración española a México. Scripta Nova, XX(531). Recuperado de http://www.ub.edu/geocrit/sn/sn-531.pdf

Rodríguez-Fariñas, M. J., Romero-Valiente, J. M., e Hidalgo-Capitán, A. L. (2016b). Los exiliados económicos. La nueva emigración española a Brasil (2008-2015). Navegar, 2(3), 137-162.

Rodríguez-Fariñas, M. J., Romero-Valiente, J. M., e Hidalgo-Capitán, A. L. (2017). Los exiliados económicos. La nueva emigración española a Argentina. Iberoamerican Journal of Development Studies, 6(2).

Romero-Valiente, J. M. (1998). Las migraciones exteriores de República Dominicana. Intercambios migratorios con España. Huelva. Servicio de Publicaciones de la Universidad de Huelva.

Romero-Valiente, J. M. (1999). Españoles en República Dominicana: proceso migratorio y perfil sociodemográfico. Estudios Sociales, 118, 85-94.

Romero-Valiente, J. M. (2003). Migraciones. En A. Arroyo Pérez (Dir.), Tendencias demográficas durante el siglo XX en España (pp. 209-253). Madrid: Instituto Nacional de Estadística y Universidad de Sevilla. 
Romero-Valiente, J. M. (2012). La movilidad exterior de los españoles y las españolas en la actualidad. Informe Final. Huelva: Fundación Universidad de Huelva y Dirección General de Migraciones.

Romero-Valiente, J. M. (2014). Migraciones. En A. Arroyo Pérez (Coord.), Una aproximación demográfica a la población extranjera en España (pp. 189-261). Madrid: Observatorio Permanente de la Inmigración y Ministerio de Empleo y Seguridad Social.

Romero-Valiente, J. M. (2016). Los flujos migratorios en las estadísticas de origen y destino: la emigración de españoles a Europa. Cuadernos Geográficos, 55(2), 151-172.

Romero-Valiente, J. M. (2017a). Patrones y diferencias sociodemográficas en el registro estadístico de la emigración española actual. Estudios Demográficos y Urbanos, 32-1(94), 163-197.

Romero-Valiente, J. M. (2017b). ¿Por qué muchos emigrantes no se inscriben en el Padrón de Españoles Residentes en el Extranjero? Lurralde, 40, 315-338.

Romero-Valiente, J. M. (2018). La emigración de españoles al extranjero (2002-2011): dimensiones y características geodemográficas. Iberoamerican Journal of Development Studies [en prensa]. Disponible en http://ried.unizar.es/index.php/revista/pages/view/enprensa

Romero-Valiente, J. M., e Hidalgo-Capitán, A. L. (2014). El subregistro consular: magnitudes y efectos en las estadísticas de emigración española. OBETS, 9(2), 377-407.

Rubio, J. (1973). Encuesta sobre las coordenadas motivacionales, socioprofesionales y culturales de la emigración española en el Languedoc. Revista Internacional de Sociología, 31(5).

Sánchez Alonso, B. (1995). Las causas de la emigración española, 1880-1930. Madrid: Alianza.

Steingress, G. (2012). Parejas mixtas e hibridación transcultural en España. Reflexiones sobre un nuevo fenómeno desde perspectivas comparativas a nivel europeo. Papers, 97(1), 11-37.

Triandafyllidou, A., y Gropas, R. (2014). "Voting With Their Feet": Highly Skilled Emigrants From Southern Europe". American Behavioral Scientist, 58(12), 1614-1633.

Triandafyllidou, A., y Issakyan, I. (Eds.) (2016). High Skill Migration and Recession. Gendered Perspectives. Reino Unido: Palgrave Macmillan.

Valero-Matas, J. A.; Coca, J. R., y Miranda-Castañeda, S. (2010). The migratory flows in Spain: an analysis of the migration and immigration input from European Union. Papeles de Población, 65, 233-256.

Vázquez, A., y Estrada, B. (1992). Causas de la emigración y tipología de emigrantes. En Historia General de la Emigración Española a Iberoamérica. Volumen 1 (pp. 201-240). Madrid: Historia 16. 
Vidal, J. A. (2005). La emigración gallega a Cuba: trayectos migratorios, inserción y movilidad laboral, 1898-1968. Madrid: Consejo Superior de Investigaciones Científicas. 